\title{
Fixação de carbono por árvores nativas da floresta estacional semi-decidual plantadas em canavial no sistema de aleias: um estudo de caso
}

Marco Rogério Gomes da Silva*

Luiz Antonio Correia Margarido**

Ricardo Coelho S. Coelho***

João Paulo Apolari****

\section{Resumo}

O presente trabalho tem como objetivo analisar o sistema de aleias, plantio de árvores em linhas associado a uma cultura agrícola, neste caso a canavieira, com três espécies de plantas de características madeireira, adubadeira e fixadora, realizando a ciclagem de nutrientes, diminuindo os efeitos da monocultura, apresentando ganhos ecológicos e ambientais. Essa técnica poderá possibilitar o aumento de renda por hectare através da fixação de carbono durante o crescimento dessas árvores, a venda da produção de madeiras e a sustentabilidade ambiental da cultura canavieira. Os parâmetros físicos utilizados na avaliação foram as medidas mensais dos diâmetros de base e de primeiro galho mais a altura do fuste de cada árvore por meio das quais foi obtido o volume de cada planta e quantificado o carbono fixado através de método não destrutivo. Essas medidas foram tiradas nos primeiros dois anos do experimento. Os resultados demonstraram que o Guapuruvú apresentou uma captura média de $685 \mathrm{~g} /$ planta de carbono, representando 1,8 vezes mais que o Cedro ( $381 \mathrm{~g} /$ planta) e 4,75 vezes mais que o Ipê ( $144 \mathrm{~g} /$ planta) no mesmo período. 0 Guapuruvú apresentou um rendimento superior em relação ao Cedro e Ipê Amarelo em crescimento das árvores e fixação de carbono, sem prejudicar o rendimento de produção de cana-de-açúcar.

Palavras Chaves: Fixação de carbono. Cana-de-açúcar. Sustentabilidade.

\section{Introdução}

A cultura canavieira está presente no Brasil desde sua colonização, quando as primeiras mudas foram trazidas pelos portugueses, inicialmente introduzida no litoral e se expandindo posteriormente por várias regiões. Atualmente o rápido crescimento da produção canavieira no Brasil está atrelado ao consumo elevado do etanol, através de novas tecnologias de aplicação, tais como a utilização em substituição a hidrocarbonetos de origem mineral e no uso como combustível automotivo. A boa cotação de preço na saca de açúcar e também a coogeração de energia fez a cultura canavieira avançar sobre novas fronteiras agrícolas. Apesar da eficiência energética da produção, a agroindústria canavieira com sistema produtivo ainda é insustentável ambientalmente.

A área total cultivada no país com cana-de-açúcar que será colhida e destinada à atividade sucroalcooleira na safra 2011/12 está estimada em 8.368,4 mil hectares. O Estado de São Paulo é o maior produtor com 52,2\% (4.370 mil hectares), seguido por Minas Gerais com 8,87\% (742,65 mil hectares), Goiás com 8,1\% (678,42 mil hectares), Paraná com 7,3\% (611,44 mil hectares), Mato Grosso do Sul com 5,70\% (480,86 mil hectares), Alagoas com 5,45\% (463,65 mil hectares), e Pernambuco com $3,89 \%$ (326,11 mil hectares). Nos demais Estados produtores, as áreas são menores, mas com bons índices de produtividade (CONAB, 2011).

A monocultura, seja da cana ou de outra cultura qualquer, costuma aumentar a produtividade agrícola e o rendimento operacional, mas também reduz da biodiversidade e prejudica o equilíbrio natural dos ecossistemas. "Serviços ambientais" como a interação biótica entre diferentes espécies 
podem deixar de acontecer. Em situações "normais", a interação biótica pode pode proporcionar benefícios como o fornecimento de nutrientes e a proteção contra predadores.

Muito se fala a respeito das mudanças climáticas, que, segundo Chang (2004), são processos naturais, considerados as escalas de tempo de milhares de anos de eras geológicas. No entanto, a velocidade e intensidade dessas mudanças a partir da Revolução Industrial têm despertado a preocupação de cientistas e líderes mundiais, principalmente nas duas últimas décadas. Esses fatos podem ser confirmados através dos relatórios do IPCC (Intergovernmental Panel on Climate Change, ou Painel Intergovernamental de Mudanças Climáticas). Os efeitos nocivos decorrentes do uso de combustíveis fósseis são uma das principais ameaças ambientais da sociedade contemporânea.

$\mathrm{O}$ aquecimento global já produz efeitos. O fenômeno seria causado pelo acúmulo de gases do chamado efeito estufa, notadamente o $\mathrm{CO}_{2}, \mathrm{CH}_{4}, \mathrm{NO}_{2}$, em uma camada ao redor do planeta, impedindo a volta da radiação dos raios infravermelhos ao espaço, aumentando assim o calor retido na atmosfera (AREVALO et al., 2002).

O Estado de São Paulo emitiu 145 milhões de toneladas de $\mathrm{CO}_{2}$ na atmosfera até 2005 e precisará cortar suas emissões em 50\% para cumprir a meta estabelecida pela Política Estadual de Mudanças Climáticas, ratificada pela Lei Estadual $\mathrm{n}^{\circ}$ 13.798, de 9 de novembro de 2009. A meta é, até 2020, reduzir as emissões em $20 \%$ em relação a 2005. Isso significa chegar a 2020 emitindo 116 milhões de toneladas de $\mathrm{CO}_{2}$ equivalente. De acordo com projeções, caso não haja mitigação de impactos, São Paulo chegará a 2020 com 238 milhões de toneladas de emissões, pouco mais que o dobro da meta (CETESB, 2011).

O maior desafio tecnológico é mudar padrões de produção de energia e de transporte. Ambos responderam por $57 \%$ das emissões em 2005 , índice que pode ser mitigado através de políticas de uso de fontes de origem vegetais. O segundo setor que mais emite gases de efeito estufa é a agricultura, com $37 \%$ do total. A indústria responde por $10 \%$, o tratamento de resíduos, por $7 \%$, e mudanças no uso da terra e de florestas, por 1\% (CETESB, 2011).

Destaca-se que a preocupação com a emissão de carbono é mundial. O esforço do Brasil em exportar combustíveis renováveis pode contribuir para reduzir a emissão de gás carbônico. A maneira mais eficiente de diminuir o efeito estufa ainda é plantar árvores, visto que essas fixam o carbono em sua biomassa por um período de tempo longo. Além disso, são conhecidas vantagens de mesclar o plantio de culturas com árvores (Farrell, 1989). Dentre essas vantagens se destacam: efeito nas condições microclimáticas (a movimentação do ar diminui, diminuindo assim a evapotranspiração); condições do solo (aumentos da matéria orgânica e consequentemente da CTC (Capacidade de Troca Catiônica), além de aumentar a umidade no solo); e componentes biológicos associados (há uma ação benéfica tanto para as plantas cultivadas, insetos benéficos e organismos do solo), além das árvores serem importante fonte de matéria prima e consequentemente de incremento de renda.

Em função dos argumentos citados, justifica-se o estudo do plantio de árvores associado à cultura da cana-de-açúcar conforme um esquema de plantio que não comprometa a mecanização nem a produtividade. $O$ plantio da cana-de-açúcar entre aleias pode ser uma opção. No sistema de aleias, são plantadas fileiras de árvores com uma distância pré-estabelecida e as culturas agrícolas são plantadas entre essas fileiras. Em solos em declive, as fileiras podem ser plantadas ao longo das curvas de nível, sem ocupar a área de cultivo agrícola. 0 cultivo em aleias também pode oferecer proteção durante chuvas irregulares, pois as fileiras de árvores ajudam a reduzir o escoamento superficial e aumentar a infiltração da água no solo. $O$ cultivo em aleias oferece nutrientes vegetais e melhora a estrutura do solo. Funciona também como quebra vento. A única questão a ser observada seria o impedimento da queima da palha, prática ainda realizada em algumas regiões, mas cuja proibição já está prevista para os próximos anos no Estado de São Paulo.

As distâncias das aleias devem ser suficientemente grandes para não causar sombreamento na cultura da cana (é conhecido que um excesso de sombra pode ser prejudicial), por isso devem ser determinadas através de experimentos controlados. Para Read (1964) e Leal (1986), distâncias entre as linhas de árvore e cultura de grãos entre $1,5 \mathrm{H}$ e $2 \mathrm{H}$, sendo $\mathrm{H}$ a altura das árvores, asseguram 
produção agrícola normal ou acima da média. Durigan e Simões (1987) comentam que a presença das árvores provoca perdas nas linhas de cultivo próximo das aleias até $1 \mathrm{H}$ e os efeitos benéficos se fazem sentir entre $2 \mathrm{H}$ e $30 \mathrm{H}$.

Este trabalho teve como objetivo estudar a implantação de estratégias de desenvolvimento rural sustentável, estimulando maior biodiversidade no canavial, minimizando impactos ambientais, sem interferir nos resultados agronômicos obtidos pelo sistema convencional.

\section{Materiais e Métodos}

\subsection{Instalação do experimento}

Em 2008, no Centro de Ciências Agrárias (CCA) da UFSCar (Universidade Federal de Lavras), localizado no Campus de Araras, em Latossolo Vermelho-Escuro (Embrapa, 1999), foram plantadas, no sistema de aleias, 10 unidades de cada uma das espécies nativas da Floresta Estacional Semidecidual (mudas de aproximadamente $1 \mathrm{~m}$ de altura). As mudas foram espaçadas cinco metros entre si, perfazendo um total de trinta árvores por aleia, com cento e cinquenta metros de comprimento para cada uma, totalizando $600 \mathrm{~m}$ lineares de aleias, numa área total de $20.250 \mathrm{~m}^{2}$. 0 cálculo da quantidade de plantas por hectare nas faixas de plantio foi feita através da quantidade de árvores por aleia em $100 \mathrm{~m}$ multiplicada pela largura da faixa de plantio (Tabela 1).

Tabela 1. Quantidade de plantas por hectare nas diferentes faixas de plantio.

\begin{tabular}{cccc}
\hline Faixas de plantio & Ipê & Cedro & Guapuruvú \\
\hline 30 metros & 66,66 & 66,66 & 66,66 \\
45 metros & 44,44 & 44,44 & 44,44 \\
60 metros & 33,33 & 33,33 & 33,33 \\
\hline
\end{tabular}

Fonte: elaboração própria.

As espécies florestais escolhidas apresentam uma ou mais das seguintes funções ecológicas:

a) adubadoras: espécies caducifólias, que incorporam matéria orgânica ao solo;

b) fixadoras de nitrogênio: espécies leguminosas, de valor comercial, com copa rala;

c) produtoras de madeira: possibilitar o corte de um sistema de manejo em longo prazo (8 a 15 anos).

Figura 1. Croqui da área experimental.

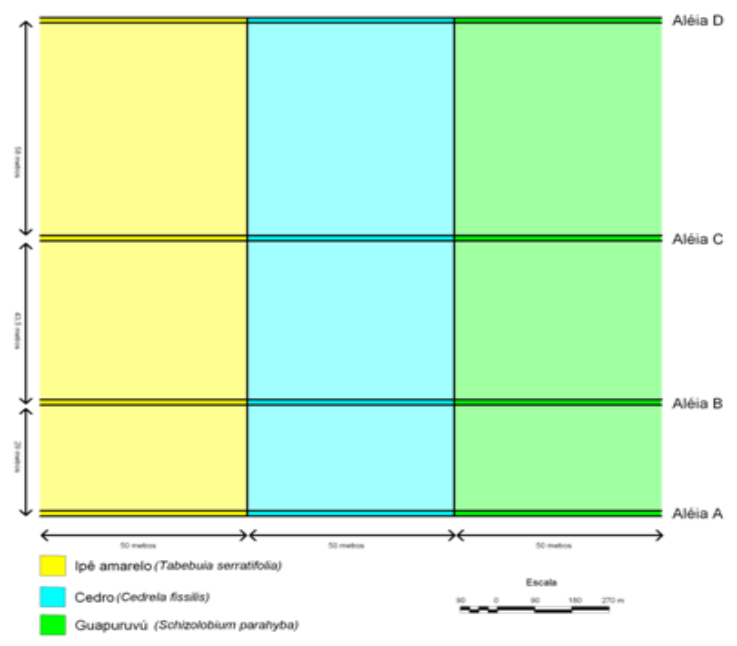

Fonte: elaboração própria.

As figuras 1 e 2 ilustram a área experimental. A área tem um total 120 árvores, já que foram plantadas 4 aleias, com distancias de $30 \mathrm{~m}$ (20 sulcos de cana); $45 \mathrm{~m}$ (30 sulcos de cana) e $60 \mathrm{~m}$ (40 sulcos de cana), sendo que essas distancias são uteis para a escolha dos espaçamento entre aleias, 
considerando que o espaçamento mais utilizado para a cana é de $1,5 \mathrm{~m}$ entre sulcos. 0 plantio das mudas das árvores foi realizado em 25/11/2008, a cana-de-açúcar da variedade RB 935744 em 31/05/2009 entre as aleias, sendo que o campo experimental foi dividido em 9 áreas. Nesse período, para não deixar o terreno desprotegido e improdutivo, as faixas de solo entre as aleias foram cultivadas com soja (Glycine max (L) Merrill.), variedade Vencedora, em cultivo convencional, observando-se uma distância de 2,5 $\mathrm{m}$ de afastamento entre as aleias e as faixas de cultivo, para não interferir no pegamento e desenvolvimento das mudas das árvores.

Figura 2. Disposição do canavial entre as aléias de árvores nativas.

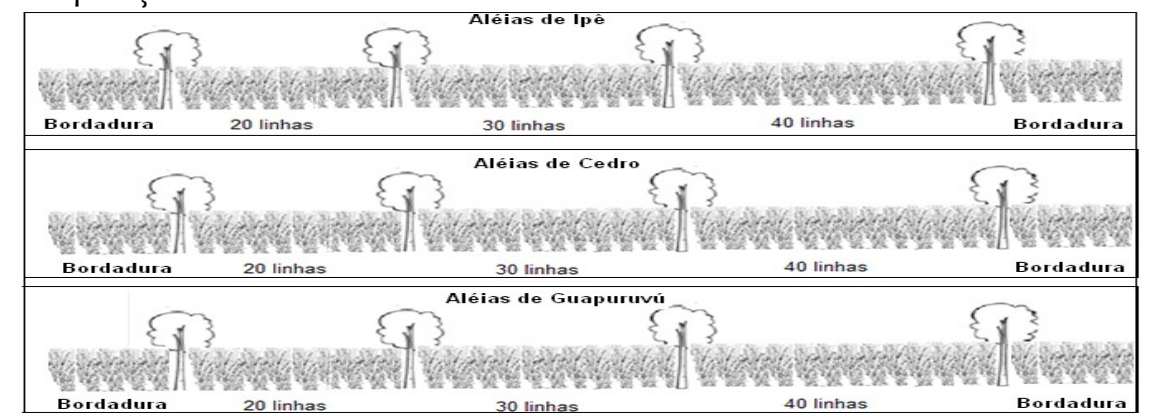

Fonte: elaboração própria.

\subsection{Monitoramento das aleias}

O trabalho foi elaborado com o intuito de avaliar a quantificação de carbono nas seguintes espécies arbóreas nativas da Floresta Estacional Semi-decidual: Cedro (Cedrela fissilis), Guapuruvú (Schizolobium parahiba) e Ipê Amarelo (Tabebuia serratifolia), plantadas em sistema de aleias em conjunto com o plantio de cana-de-açúcar. As duas primeiras espécies foram escolhidas por apresentarem as características descritas na instalação do experimento, já o ipê-amarelo, mesmo necessitando de um tempo maior para o seu aproveitamento econômico, foi escolhido em função do alto valor comercial de sua madeira e também pela sua importância na paisagem. A madeira do Cedro possui densidade aparente entre 0,47 e $0,61 \mathrm{~g} / \mathrm{cm}^{3}$, o Guapuruvú é uma madeira de baixa densidade aparente de 0,2 a $0,3 \mathrm{~g} / \mathrm{cm}^{3}$ e o Ipê Amarelo com densidade verde de $1,15 \mathrm{a} 1.3 \mathrm{~g} / \mathrm{cm}^{3}$. Esses valores de densidade foram extraídos do banco de dados do IBAMA (2011) e do IPEF (2011), que lista a densidade verde de diversas espécies de madeiras brasileiras.

Como parâmetro silviculturais do sistema agroflorestal, foi efetuado o monitoramento mensal da altura total, altura do fuste, sanidade, brotação e fenologia do crescimento das espécies florestais e as alterações nas condições climáticas locais.

Entre os modelos para estimar os volumes de biomassa arbórea, por inferências de suas principais medidas biométricas, como altura, DAP e densidade da madeira ou da espécie arbórea, optou-se por uma metodologia não destrutiva, ou indireta, pois o crescimento destas árvores deverá ser acompanhado por outros pesquisadores.

O volume comercial foi obtido pela medição indireta mensal dos parâmetros altura e volume das árvores em pé. Essas medidas foram realizadas com uma régua de madeira de 4 metros com seções graduadas em 1 centímetro da marca Posenhaim (régua de topografia) e paquímetro universal de $200 \mathrm{~mm}$ com seções graduadas em 1 milímetro da marca Mitutoyo. Foi computado também o número de árvores que morreram em cada aleia. Para o cálculo de volume estimado de madeira com casca (V), empregou-se a fórmula de Smalian (LOETSCH et al., 1973), transformando os correspondentes diâmetros em áreas seccionais (A1, A2), e o respectivo comprimento ou altura (C) do fuste:

Onde:

$$
V=\left(\frac{A 1+A 2}{2}\right) C
$$

$\mathrm{V}=$ volume da seção do tronco, $\mathrm{em} \mathrm{cm}^{3}$;

A1 = área transversal da seção de maior diâmetro (base); 
A2 = área transversal de menor diâmetro ( $1^{\circ}$ galho);

$\mathrm{C}=$ comprimento da seção (altura até o $1^{\circ}$ galho).

A área transversal de cada seção é dada pela expressão $A=\Pi \cdot\left(\frac{d 2}{4}\right)$ representa o diâmetro da seção.

Para cada espécie foi aplicada a equação alométrica, obtendo-se o valor da quantificação do carbono incorporado na biomassa comercial. Utilizou-se o fator de conversão para estimar o valor de carbono total estimado de $48 \%$ na biomassa seca. Segundo Higuchi et al. (1998), a equação alométrica utilizada refere-se ao cálculo de massa fresca da árvore. $60 \%$ desse valor correspondem à biomassa seca, e os $40 \%$ restantes são água. Esses mesmos valores são citados por ARAÚJO et al. (1999). No presente artigo, foi utilizada a densidade aparente de cada espécie madeireira, sendo aplicado o fator 1,3 para o Ipê Amarelo, 0,6 para o Cedro e 0,3 para o Guapuruvú.

$O$ cálculo para obter o estoque de carbono foi:

Onde:

$$
C B C(\mathrm{~g} / \text { planta })=[(V B V C \cdot D M) \cdot 0,6] \cdot 0,48
$$

$\mathrm{CBC}(\mathrm{g} /$ planta $)=$ carbono na biomassa comercial em gramas

VBVC = Volume da biomassa vegetal comercial

$\mathrm{DM}=$ Densidade da madeira verde

$0,6=$ Fator de biomassa seca

$0,48=$ Fator de $\%$ Carbono

Esse modelo matemática, que utiliza variáveis de fácil obtenção que não requerem a destruição das plantes antes de sua idade de comercialização, mostrou-se eficiente para estimar a quantidade de carbono fixado.

\subsection{Monitoramento da cana-de-açúcar}

Todas as canas de todas as 90 linhas de $150 \mathrm{~m}$ do experimento, totalizando $13.500 \mathrm{~m}$ lineares, foram contadas com o auxílio de contadores manuais mecânicos. Após as contagens foram retiradas três amostras de 15 canas consecutivas, em cada segmento de $50 \mathrm{~m}$, correspondentes às faixas de cana entre as aleias de cada espécie de árvore.

Essas amostras foram etiquetadas, retiradas do canavial e pesadas ainda no campo com uma balança eletrônica portátil marca LIDER, Modelo PR30/500, fixada em um tripé de ferro. A partir do número real de colmos das canas de cada linha mais o peso médio das mesmas obtidas nas amostragens foi estimada a produtividade em toneladas por hectare de cada linha em toda área experimental. A partir desses dados foi possível calcular a produtividade da cana-de-açúcar nas linhas de cultivo em diferentes distâncias das linhas das árvores.

A colheita da cana foi realizada mecanicamente de forma convencional em 23/10/2010. A única alteração realizada foi o tombamento manual das linhas de cana vizinhas das aleias para evitar possíveis injúrias da colheitadeira às árvores.

\section{Resultados e discussão}

\subsection{Desenvolvimento das árvores.}

As árvores desenvolveram-se normalmente não havendo solução de continuidade no ganho de altura relacionado ao sistema de cultivo aos quais foram submetidas (Tabela 2). As únicas interferências negativas foram observadas quanto ao incremento de altura, que ocorreram nas árvores de Cedro porque algumas sofreram o ataque da broca do ponteiro, o lepidóptero Hypsipyla grandella (Zeller,1848) (Lepidoptera: Pyralidae), entre fevereiro de 2009 e maio de 2010, o que interferiu no crescimento em altura das plantas. Essas ocorrências eram de certa forma esperadas, pois segundo Dourojeami (1973), a susceptibilidade de algumas espécies da família meliácea é bastante conhecida na literatura: mogno, cedro, andiroba são conhecidas como hospedeiras de insetos lepidópteros da família Pyralidae (Hypsipyla grandella, Hypsipyla ferrealis, Sematoneura grijpinai, 
Fixação de carbono por árvores nativas da Floresta Estacional Semi-decidual plantadas em canavial no sistema de aleias: um estudo de caso

Humiphila paleolivacea), sendo a H. grandella uma praga cosmopolita, encontrada em todas as regiões geográficas ocupadas pelas meliáceas mencionadas (Conde, 2006).

Tabela 2. Altura média das árvores nas aléias.

\begin{tabular}{cccc}
\hline $\begin{array}{c}\text { Data da } \\
\text { Amostragem }\end{array}$ & $\begin{array}{c}\text { Ipê } \\
(\mathrm{m})\end{array}$ & $\begin{array}{c}\text { Cedro } \\
(\mathrm{m})\end{array}$ & $\begin{array}{c}\text { Guapuruvú } \\
(\mathrm{m})\end{array}$ \\
\hline $05 / 09$ & 1,17 & 1,40 & 1,16 \\
$08 / 09$ & 1,22 & 1,41 & 1,30 \\
$11 / 09$ & 1,58 & 1,78 & 1,66 \\
$02 / 10$ & 1,99 & 1,60 & 1,99 \\
$05 / 10$ & 2,20 & 1,58 & 2,44 \\
$08 / 10$ & 2,25 & 1,77 & 2,70 \\
$10 / 10$ & 2,45 & 1,81 & 2,84 \\
\hline
\end{tabular}

Fonte: elaboração própria.

Como o sistema aleias-cana pode ser caracterizado como policultivo, esperava-se que o ataque dessa praga fosse amenizado pela redução da visibilidade e da não preferência pelos outros componentes do sistema, conforme aventado por Altiere (2004). De certa forma, parece que esse fenômeno pode ter ocorrido, pois, a partir de maio de 2010, o canavial sobrepujava em altura as árvores, ocultando-as, e o ataque da praga deixou de ocorrer, embora as condições climáticas e o ciclo biológico do inseto também possam servir de explicação. Foi a partir dessa época que as árvores de Cedro retomaram o desenvolvimento, embora numa curva de crescimento mais lento (Figura 3). Uma vez que a cana-de-açúcar foi removida pela colheita, as árvores voltaram a ser totalmente visíveis por determinado período, fazendo com o que o ataque por pragas possa se repetir. Conforme Paiva e Poggiani (2000), a luminosidade em céu aberto e sob dossel, a luminosidade relativa em diferentes épocas do ano e a umidade do solo influenciam o desenvolvimento de mudas de cedro. Esses quatro fatores estiveram presentes neste experimento, além da praga, mas apenas o Cedro apresentou o ataque e a alteração nas curvas de crescimento. Por isso mais observações nesses aspetos deverão ser realizadas em etapas posteriores deste experimento.

Não houve mortalidade de mudas de Ipê, e as mudas de Cedro, embora atingidas pela broca dos ponteiros, apresentaram mortalidade de 2,5\%, enquanto as mudas de Guapuruvú apresentaram 17,5\% de mortalidade. Essa mortalidade, porém foi localizada, restringindo-se a dois segmentos de aléias devido o ataque de brocas na raiz (Tabela 3).

Figura 3. Crescimento em altura das árvores nas aléias.

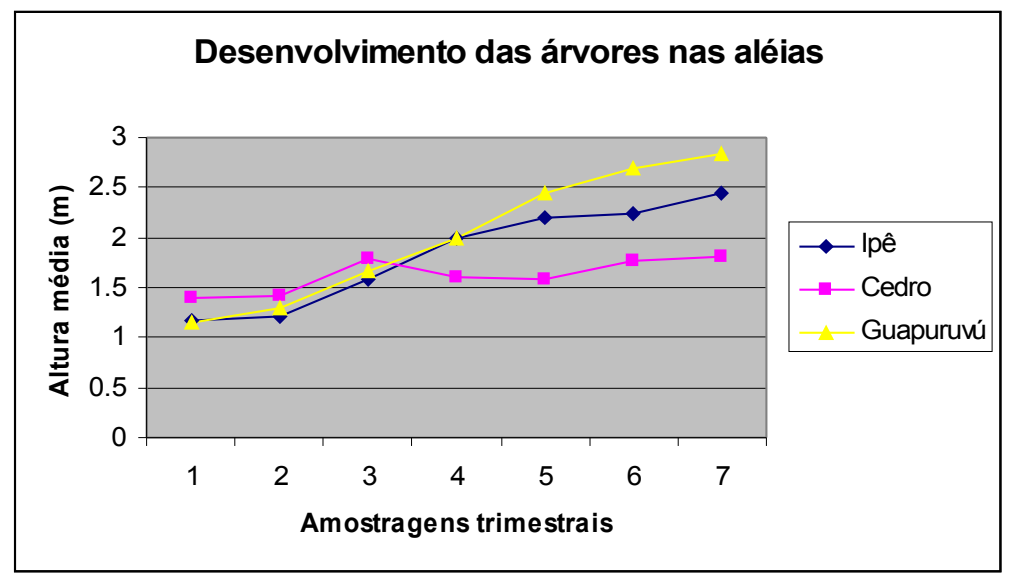

Fonte: elaboração própria. 
Tabela 3. Porcentagem de mortalidade de mudas em outubro de 2010. $\left({ }^{*}\right)$

\begin{tabular}{llll}
\hline Mudas de árvores & Ipê & Cedro & Guapuruvú \\
\hline Plantadas & 40 & 40 & 40 \\
Mortas & 0 & 1 & 7 \\
$\%$ mortalidade & $0.0 \%$ & $2.5 \%$ & $17.5 \%$ \\
\hline
\end{tabular}

$\left({ }^{*}\right)$ mudas com 23 meses de transplante. Fonte: Elaboração própria.

\subsection{Desenvolvimento do canavial.}

O canavial desenvolveu-se normalmente sem intercorrência e todas as práticas agrícolas convencionais foram empregadas sem maiores dificuldades. A produção média entre as diferentes larguras de faixa, sem considerar as espécies das árvores, variou entre $132.5 \mathrm{a} 158.9 \mathrm{t} / \mathrm{ha}$. Quando se analisam as espécies de árvores sem considerar as larguras das faixas, a produção média variou entre 133,9 a 156,0 t/ha, sendo que a média geral de todo o experimento foi de 141,6 t/ha (Tabela 4). Considerando que o cultivo neste experimento simulou as técnicas de um cultivo comercial, os resultados gerais obtidos indicam uma produtividade média normal para canas em plantio de ano e meio.

Tabela 4. Produtividade média de cana-de-açúcar em $\mathrm{t} /$ ha nas diferentes faixas

\begin{tabular}{ccccc}
\hline $\begin{array}{c}\text { Faixas de } \\
\text { plantio }\end{array}$ & Ipê & Cedro & Guapuruvú & Médias \\
\hline 20 linhas & 134,8 & 138,9 & 125,8 & 133,2 \\
30 linhas & 198,2 & 137,1 & 141,4 & 158,9 \\
40 linhas & 134,9 & 128,2 & 134,6 & 132,6 \\
Médias & 156,0 & 134,7 & 133,9 & 141,6 \\
\hline
\end{tabular}

Fonte: elaboração própria.

\subsection{Fixação do Carbono}

A fixação de carbono nos primeiros 24 meses foi relativamente pequena, uma vez que abrangeu a fase inicial do desenvolvimento vegetativo das árvores. Mesmo assim, foi possível detectar diferenças de comportamento entre as espécies estudadas a partir do $12^{\circ}$ mês de observação. Notadamente, o Guapuruvú apresentou uma produção de biomassa maior quando comparado ao Ipê e ao Cedro.

Durante os primeiros 24 meses do experimento, verifica-se que existem distinções marcantes entre as espécies vegetais estudadas em todas as aleias estudadas (Figuras 4, 5, 6 e 7) independente dos espaçamentos empregados (Tabela 5). A espécie Guapuruvú apresentou uma captura media de $685 \mathrm{~g} /$ planta de carbono, representando 1,8 vezes mais que o Cedro (381 g/planta) e 4,75 vezes mais que o Ipê (144 g/planta) no mesmo período estudado. Além da espécie vegetal, outro aspecto a ser levado em conta é o espaçamento a ser adotado. Há grande diferença quando se considera essas duas variáveis. O Ipê com espaçamento $60 \mathrm{~m}$ capturou apenas $4,799 \mathrm{~kg} / \mathrm{ha}$ de carbono enquanto o Guapuruvú com espaçamento de $30 \mathrm{~m}$ capturou 45,679 kg/ha de carbono, ou seja, uma eficiência 9,51 vezes superior (Tabela 6).

Figura 4. Fixação de carbono das árvores na aléia $A$.

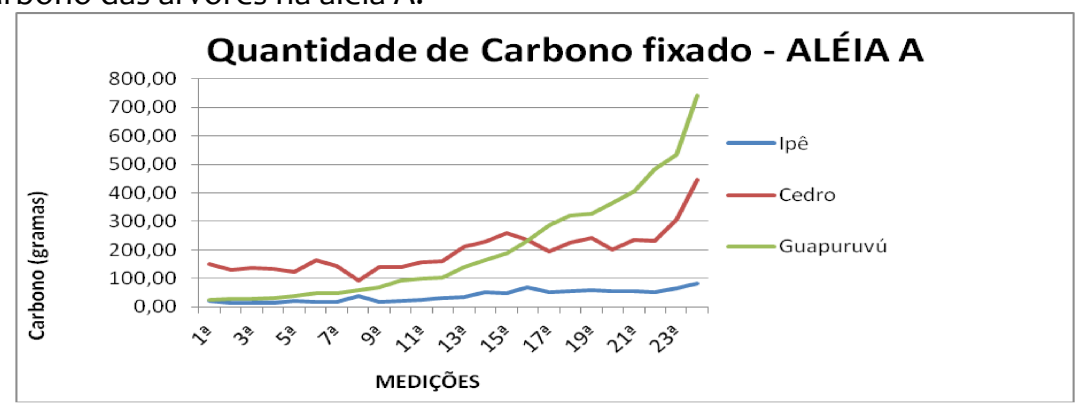

Fonte: elaboração própria. 
Figura 5. Fixação de carbono das árvores na aléia B.

\section{Quantidade de Carbono fixado - ALÉIA B}

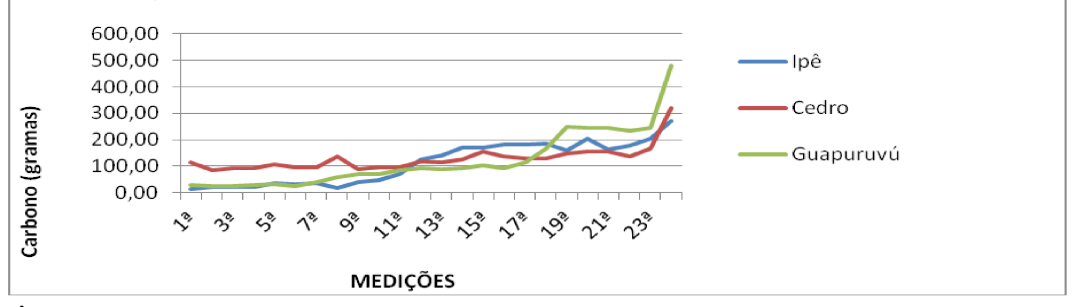

Fonte: elaboração própria.

Figura 6. Fixação de carbono das árvores na aléia C.

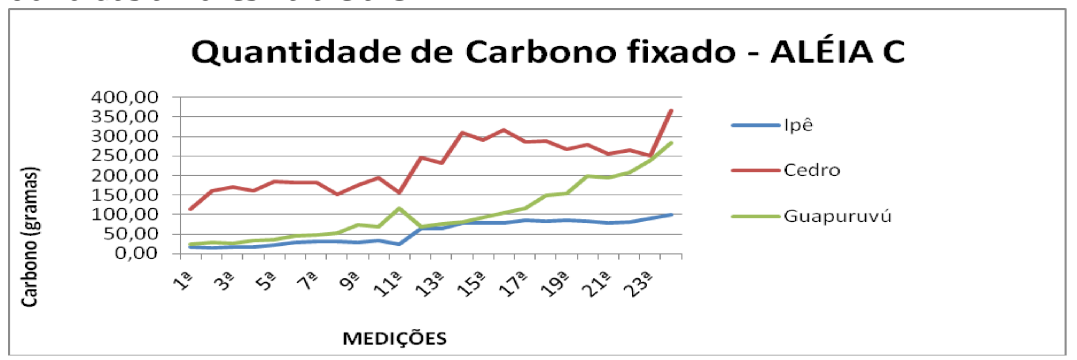

Fonte: elaboração própria.

Figura 7. Fixação de carbono das árvores na aléia D.

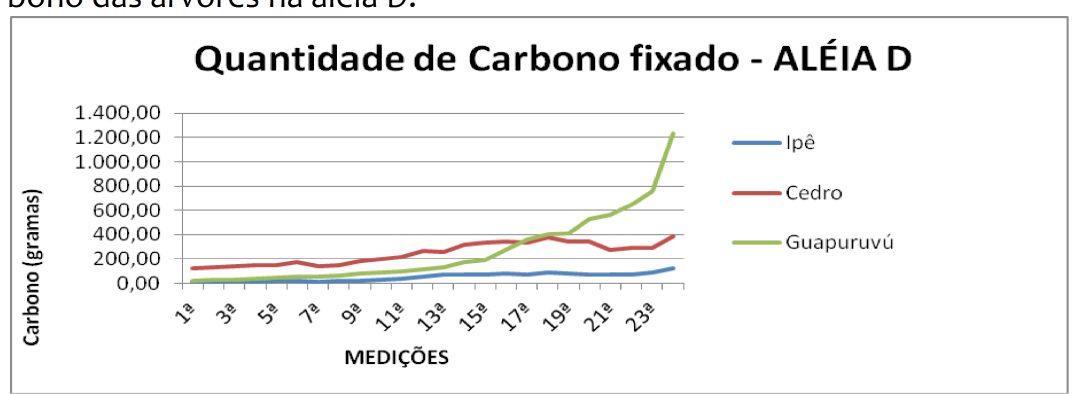

Fonte: elaboração própria.

Tabela 5. Fixação de carbono em gramas / planta nas diferentes faixas na $24^{a}$ medição.

\begin{tabular}{cccc}
\hline Aléia & Ipê & Cedro & Guapuruvú \\
\hline A & 84,0 & 446,0 & 742,0 \\
B & 272,0 & 321,0 & 480,0 \\
C & 100,0 & 366,0 & 284,0 \\
D & 120,0 & 390,0 & 1235,0 \\
Médias & $\mathbf{1 4 4 , 0}$ & 381,0 & 685,0 \\
\hline
\end{tabular}

Fonte: elaboração própria.

Tabela 6. Fixação de carbono em Kilogramas por ha nas diferentes faixas na $24^{\mathrm{a}}$ medição.

Fonte: elaboração própria.

\begin{tabular}{cccc}
\hline Espaçamentos & Ipê & Cedro & Guapuruvú \\
\hline $30 \mathrm{~m}$ & 9,599 & 25,380 & 45,679 \\
$45 \mathrm{~m}$ & 6,399 & 16,920 & 30,452 \\
$60 \mathrm{~m}$ & 4,799 & 12,690 & 22,839 \\
\hline
\end{tabular}




\title{
4 Conclusões
}

Com base nos dados obtidos, para os dois primeiros anos de observação, conclui-se que:

a) é tecnicamente possível a implantação de canaviais em sistema de aléias com árvores nativas sem prejuízo agronômico da produção da cana-de-açúcar;

b) as espécies de árvores nativas estudadas desenvolveram-se normalmente nas condições do experimento com baixa taxa de mortalidade;

c) foram observadas diferenças entre as espécies de árvores estudadas quanto a captura de carbono sendo o Guapuruvú 1,79 vezes mais eficiente que o Cedro e 4,75 vezes mais eficiente que o Ipê, enquanto que o Cedro foi 2,64 mais eficiente que o Ipê Amarelo;

d) as interações entre espécies arbóreas e espaçamentos apresentaram diferenças elevadas quanto a quantidade de carbono capturado por hectare, oscilando numa taxa da ordem de $951 \%$.

Cabe destacar que os dados obtidos são preliminares, pois se referem a apenas dois anos. 0 sistema deverá ser estudado por um período maior.

\section{Carbon sequestration by trees native to the semi- deciduous seasonal forest plantation planted in the alley cropping system: a case study}

\begin{abstract}
The present work aims to analyze the system of alleys, planting trees in rows associated with a crop, in this case sugar cane, with three plant species characteristic of timber, and adubadeira fixative, making nutrient cycling, reducing the effects monoculture, with ecological and environmental gains. This technique will allow the increase of income per hectare by fixing carbon during the growth period of these trees, besides the sale of wood production and promote the environmental sustainability of sugar cane. The parameters used to evaluate physical measurements were monthly during the first 2 years of experiment established, base diameter and the first branch plus the height of the stem of each plant, to thereby obtain the amount of each plant, to quantify the fixed carbon by of non-destructive method. The results showed that the Guapuruvu capture media showed a 685 $\mathrm{g} /$ plant carbon, representing more than 1.8 times the cedar ( $381 \mathrm{~g} /$ plant) and 4.75 times the Ipê (144 g / plant) in the same period. The Guapuruvu showed a yield higher than the Cedar and Yellow Ipê, both in tree growth and carbon fixation in this evaluation period, without affecting the yield of production of cane sugar.

Keywords: Alleys. Carbon sequestration. Sugar cane. Sustainability.

\footnotetext{
* Mestrando de Agroecologia do PPGADR/UFSCar/Araras-SP, marcogomes@tegaconsultoria.com.br

** CCA/UFSCar (Centro de Ciências Agrárias da Universidade Federal de São Carlos), Araras, SP, Departamento de Tecnologia Agroindustrial e Socioeconômica Rural, marga@cca.ufscar.br

*** CCA/UFSCar (Centro de Ciências Agrárias da Universidade Federal de São Carlos), Araras, SP, Departamento de Tecnologia Agro-industrial e Socioeconômica Rural, coelhocitrus@yahoo.com.br

**** CCA/UFSCar (Centro de Ciências Agrárias da Universidade Federal de São Carlos), Araras, SP, Departamento de Tecnologia Agro-industrial e Socioeconômica Rural, jpapolari@yahoo.com.br
}

\section{Referencias bibliográficas}

ALTIERI, Miguel. Agroecologia: a dinâmica produtiva da agricultura sustentável. 4ed. Porto Alegre, RS: Editora da UFRGS, 2004. 
Fixação de carbono por árvores nativas da Floresta Estacional Semi-decidual plantadas em canavial no sistema de aleias: um estudo de caso

ARAÚJO, T.M.; CARVALHO Jr., J.A.; HIGUCHI, N.; BRASIL Jr., A.C.P. \& Mesquita, A.L.A. 1999. A tropical rain forest clearing experiment by biomass burning in the state of Pará, Brazil. Atmospheric Environment, 33: 1991-1998.

AREVALO, L. A; ALEGRE, C. J; e VILCAHUAMAN L. J. M. Metodologia para estimar o estoque de carbono em diferentes sistemas de uso da terra, Colombo - PR: Embrapa Florestas, 2002.

CETESB - Companhia Ambiental do Estado de São Paulo. 1ํㅡㄴ Inventário de emissões antrópicas de gases de efeito estufa diretos e indiretos do Estado de São Paulo, 2 ed. São Paulo: CETESB, 2011.

CHANG, M.Y. Seqüestro florestal de carbono no Brasil: dimensões políticas socioeconômicas e ecológicas. In: Fixação de carbono: atualidades, projetos e pesquisas, 2004, Curitiba. Anais... Curitiba, 2004. p.15-37

CONAB - Companhia Nacional de Abastecimento. Acompanhamento da safra brasileira. Disponível em: <http://www.conab.gov.br/OlalaCMS/uploads/arquivos/11_12_08_11_00_54_08.pdf>. Acesso em: 2 dez. 2011.

CONDE, R. A. R. Controle silvicultural e mecânico da broca do mogno Hypsipyla grandella (Zeller, 1848) (Lepdoptera: Pyralidae) em sistema agroflorestal. 2006. 72 f. Dissertação (Mestrado em Agronomia) - Universidade Federal Rural da Amazônia, Belém, PA.

DOUROJEAMI, M.J. Considerações sobre el problema Hypsipyla grandella (Zeller) em las plantaciones de Meliaceae em el Peru. Chemistry and chemical taxonomy of the rutales. Proceedings First Symposium on Integrated Control of Hypsipyla, (CATIE) II. Turrialba, Costa Rica. P. 60-62, 1973.

DURIGAN, G.; SIMÕES, J. W. Quebra-ventos de Grevillea robusta A. Cunn.: efeitos sobre a velocidade do vento, umidade do solo e produção do café. IPEF, Piracicaba, n. 36, p. 27-34, 1987.

EMBRAPA SOLOS. Sistema brasileiro de classificação de solos. Rio de Janeiro, 1999. 412 p.

FARRELL, J.G. In: ALTIERI, M.A. Agroecologia: as bases científicas da agricultura alternativa. Rio de Janeiro: PTA/FASE, 1989. 240p.

IBAMA - Instituto Brasileiro do Meio Ambiente e dos Recursos Naturais Renováveis. Disponível em <http://www.ibama.gov.br/lpf/madeira/>. Acesso em 2 dez. 2011.

IPEF - Instituto de Pesquisas e Estudos Florestais. Disponível em:

<http://www.ipef.br/identificacao/nativas/>. Acesso em 2 dez. 2011.

HIGUCHI, N.; SANTOS, J.; RIBEIRO, R.J.; MINETTE, L.; BIOT, Y. 1998. Biomassa da parte aérea da vegetação de floresta tropical úmida de terra-firme da Amazônia Brasileira. Acta Amazonica, 28 (2): 153-165.

LEAL, A. C. Quebra-ventos arbóreos: aspectos fundamentais de uma técnica altamente promissora. Curitiba: IAPAR, 1986. (Informe de Pesquisa, n. 67). Disponível em:

<http://www.iapar.br/arquivos/File/zip_pdf/IP67.pdf>. Acesso: 3 dez. 2009.

LOETSCH, F.; ZÖHRER, F.; HALLER, K. E. Forest inventory. Munich: BLV, 1973. v.2. 469p.

PAIVA AV; POGGIANI F. 2000. Crescimento de mudas de espécies arbóreas nativas plantadas no sub-bosque de um fragmento florestal. Scientia Forestalis 57: 141-151.

READ, R. A. Tree windbreakers for the central great plains. Washington, USDA, Forest service, 1964, 68p. (USDA. Forest Service. Agriculture Handbook, 250). 